The fact that identical results are found for the same species taken from different fishing places supports the application of serology to taxonomic investigations. The non-typical reaction with antigen of young three-spined sticklebacks is also in agreement with work already published.

Tadeusz Penczak

Department of Taxonomic Zoology,

University of Łódź, Poland.

${ }^{1}$ Leiner, M., Z. Morph. u. Ökol., 28, 108 (1934).

${ }^{2}$ Schindler, O., Unsere Süsswasserfische, 160, edit. by Kosmos, F. V. (Stuttgart, 1953)

${ }^{3}$ Taliev, D. N., Trav. Stat. limn. Bajkal (Leningrad), 10, 268 (1940).

- Taliev, D. N., Trav. Inst. Zool. Acad. Sci. (Moscow). 8, 43 (1946).

${ }^{5}$ Pora, E. A., Inst. Oceanograph. (Monaco), 699, 1 (1936).

- O'Rourke, F, J., Nature, 183, 1192 (1959).

7 O'Rourke, F. J., Irish J. Med. Sei., 77 (1980).

\section{Biotin, a Growth Requirement for Four Soil Amcebæ}

SUBSEQUENT to the publication of Adam's defined medium for the growth of Neff's Acanthamoeba sp. ${ }^{1}$, I attempted to grow Hartmannella rhysodes in this medium slightly modified in the concentrations of amino-acids ${ }^{2}$. A further modification of Adam's medium was also tried in which all the aminoacids used were natural isomers ( $\mathrm{L}$ forms), except threonine, valine and serine which were used as racemic mixtures (DL forms), and the methionine concentration was halved $(13.5 \mathrm{mgm}$. $/ 100 \mathrm{ml}$.). All organic nutrients were obtained from the California Corporation for Biochemical Research (Los Angeles); the amino-acids used were 'A grade' except DL-isoleucine ('C grade'). The culture methods have been described previously ${ }^{8}$. Both modifications of Adam's medium failed to support growth of this hartmannellid amoba past the second or third serial culture using either glucose or sodium acetate as the carbon source. When biotin was added $(0.5 \mu \mathrm{gm} . / 100 \mathrm{ml}$. $)$, satisfactory growth was obtained in serial cultures. The average maximum yield for duplicate cultures in the defined medium, containing $0.1 M$ glucose and grown at $30^{\circ} \mathrm{C}$. on a rotary shaker, was $5.76 \times 10^{8}$ organisms $/ \mathrm{ml}$. and the mean generation time was c. $40 \mathrm{hr}$. This is comparable to growth in the proteose peptone (Difco, Detroit)-glucose medium ${ }^{3}$. Identical results have been obtained with Neff's Acanthamoeba sp., Acanthamoeba castellanii and Mayorella palestinensis in both modifications of Adam's medium with either glucose or sodium acetate as the carbon source. Therefore all four soil amœbæ appear to require biotin in addition to the vitamins already present in Adam's medium (thiamine and $\mathrm{B}_{12}$ ).

In order to establish whether biotin is a true requirement for the growth of these amœbæ or an artefact peculiar to the defined medium in my laboratory, I used 'Avidin' to bind biotin ${ }^{4}$ in the proteose peptone-glucose medium (PPG) described previously ${ }^{3}$. 'Avidin' (Nutritional Biochemicals Corporation, Cleveland, containing c. 1,000-2,000 units/gm.) was added to the PPG medium in a concentration of $4 \mathrm{mgm} . / 100 \mathrm{ml}$. The 'Avidin'-treated medium (PPG-A) and the controls were filter-sterilized. All four soil amœbæ mentioned above were carried in serial cultures of the PPG-A medium. Both the PPG medium and the PPG-A medium, supplemented with enough biotin to saturate the added 'Avidin' (10 $\mu \mathrm{gm} . / 100 \mathrm{ml}$.), were used as controls. At each subculture of the serial cultures explants were made into both control media. The PPG-A medium failed to support the growth of all four soil amœbæ past the second or third serial culture, whereas growth occurred in the explant controls. The experiments were carried out in duplicate on a shaker ${ }^{3}$ and in stationary, slanted test-tube cultures at $30^{\circ} \mathrm{C}$.

At present it is not possible to explain the apparent lack of a biotin requirement in the defined medium described by Adam ${ }^{1,2}$ for Neff's Acanthamoeba sp. The observations given in the present report indicate that, in my laboratory, Neff's Acanthamoeba sp., as well as Hartmannella rhysodes, Acanthamoeba castel. lanii and Mayorella palestinensis, require biotin for growth in the defined medium and in the undefined proteose peptone-glucose medium.

This work was supported by grants from the Research Corporation (Brown-Hazen Fund) and the National Research Council of Canada.

R. N. BAND

Department of Zoology,

University of British Columbia, Vancouver, B.C.

${ }^{1}$ Adam, K. M. G., J. Gen. Microbiol., 21, 519 (1959).

${ }^{2}$ Adam, K. M. G. (personal communication).

3 Band, R. N., J. Gen. Microbiol., 21, 80 (1959).

4 György, P., in The Vitamins, 1, 527 (Acad. Press, New York, 1954).

\section{Effect of Ribonuclease on Shell Regeneration in Ariophanta sp.}

IT is supposed that the process of shell growth in molluses consists of two phases. During the first step there is the elaboration of a protein membrane, and in the second mineralization of this membrane takes place ${ }^{1,2}$. Wagge has suggested that in Helix aspersa, which can rapidly repair its shell if this be damaged, the regeneration of the shell is brought about by the amœebocytes, which first lay down an organic framework that later on becomes calcified. Since ribonucleic acid is concerned with synthesis of proteins $\mathrm{s}^{8,4}$, which in this case form an integral part of the shell, we have tried to assess its role in the regeneration of the shell in the snail Arinphanta sp. (Pulmonata).

For experimental work adult snails were chosen, and into each was injected $0 \cdot 5 \mathrm{ml}$. of distilled water containing $2 \mathrm{mgm}$. of ribonuclease (Armour, cryst. alline). Prior to injection, the enzyme solution was placed in a water-bath at $70^{\circ} \mathrm{C}$. for $20 \mathrm{~min}$. so as to destroy the proteolytic activity present in the ribonuclease preparation. The control specimens received $0.5 \mathrm{ml}$. of distilled water only. Pieces of shell (slightly less than $1 \mathrm{~cm} .{ }^{2}$ ) about $2 \mathrm{~cm}$. away from the mouth of the shell were removed. Eighty snails were used, of which 40 served as controls. After injection, the animals were placed in glass bowls with wet filter papers at the top and bottom of the bowl so as to saturate the air with water vapour. They were not fed during the period of regeneration. Observations were made on the nature of the regenerating pieces at intervals of 24,48 and $72 \mathrm{hr}$., after which parts of the shells with the regenerating pieces in the centre were cut from the specimens treated with ribonuclease and from controls. They were wiped dry and dehydrated in an air oven. The area of the regenerated piece was measured by an occular reticule. Later, the regenerated piece was carefully cut out and weighed. From this, the weight of the regenerated piece per $1 \mathrm{~cm}^{2}$ was calculated for both the treated and the control specimens.

Examination of the regenerated shell showed that the process of calcification was considerably inhibited 